Western University

Scholarship@Western

Department of Economics Research Reports

Economics Working Papers Archive

1970

\title{
Intermediate Goods in International Trade with Variable Proportions and Two Primary Inputs
}

Robert D. Warne

Follow this and additional works at: https://ir.lib.uwo.ca/economicsresrpt

Part of the Economics Commons

Citation of this paper:

Warne, Robert D.. "Intermediate Goods in International Trade with Variable Proportions and Two Primary Inputs." Department of Economics Research Reports, 7005. London, ON: Department of Economics, University of Western Ontario (1970). 
RESEARCH REPORT 7005

\section{INTERMEDIATE GOODS IN INTERNATIONAL TRADE \\ WITH VARIABLE PROPORTIONS \\ AND TWO PRIMARY INPUTS}

by

Robert D. Warne 
INTERMEDIATE GOODS IN INTERNATIONAL TRADE WITH

VARIABLE PROPORTIONS AND IWO PRIMARY INPUTS*

Robert D. Warne

\section{INTRODUCTION}

Most international trade theory has been built on the assumption that outputs of production processes are not used as inputs of other processes. Yet intermediate goods play an obvious role in world trade, both as goods that are directly traded and in the production of traded final goods. Recently, however, the effects of incorporating intermediate goods into the traditional theory have begun to receive more attention. There have been two main diagrammatic approaches to this problem. It is the purpose of this paper to show that the two can easily be synthesized into a more general model, which will then be used to examine some of the conclusions reached in the specific cases. The next two sections will give a brief sketch of the two existing approaches to intermediate goods.

\section{THE TWO FACTOR, FIXED PROPORTIONS MODEL}

Vanek $^{1}$ has developed. a simple geometrical technique for handling intermediate inputs that are used in fixed proportions to output. He superimposes on the traditional two primary-factor, two final-good approach (in which the factors are in fixed supply and between which substitution is allowed) the constraint that each good is required in the production of of the other in fixed proportion to the total output of the industry.

*I would like to thank Professor James R. Melvin for his help at all stages of this paper. He is not, of course, to be held responsible for any errors. I would also like to acknowledge a Canada Council grant received by Professor Melvin which helped finance the research for this paper.

1Jaroslav Vanek, "Variable Factor Proportions and Interindustry Flows in the Theory of International Trade," Quarterly Journal of Economics, IXXVII (Feb., 1963). 
Thus added to the usual model (1) in which the primary factors are $I$ and $K$ and the final goods are $x_{1}$ and $x_{2}$, are the additional relationships (2) where $x_{1}$ and $x_{2}$ now serve as both an intermediate and a final good and where the lower case ' $x$ ' denotes net output. The first subscripts refer to the producing industry, the second to the using industry.

$$
\begin{aligned}
& x_{1}=f_{1}\left(L_{1}, K_{1}\right) \\
& x_{2}=f_{2}\left(L_{2}, K_{2}\right) \\
& L_{1}+L_{2}=I \\
& K_{1}+K_{2}=k \\
& x_{1}=x_{1}-a_{12} x_{2} \\
& x_{2}=x_{2}-a_{21} x_{1}
\end{aligned}
$$

Vanek then constructs the gross and net production possibility curves (hereafter referred to as gross and net curves). Figure 1, except for notation, is the same as his Figure $1 .^{2}$ The gross curve can be constructed as usual from (1) without reference to (2). It can be thought to represent the total amount of $x_{1}$ and $x_{2}$ produced or the quantities that could be produced if intermediate inputs were not required for production. We shall see below that these two interpretations are not equivalent in the variable proportions case. Using (2), the net production possibility curve is easily derived from the gross curve. If the economy produces at $\mathrm{E}$, $\mathrm{RS}$ of $\mathrm{X}_{2}$ $\left(a_{21} \mathrm{OU}\right)$ and $\mathrm{TU}$ of $\mathrm{x}_{1}\left(\mathrm{a}_{12} \mathrm{OR}\right)$ are used up in production, and thus the amount 


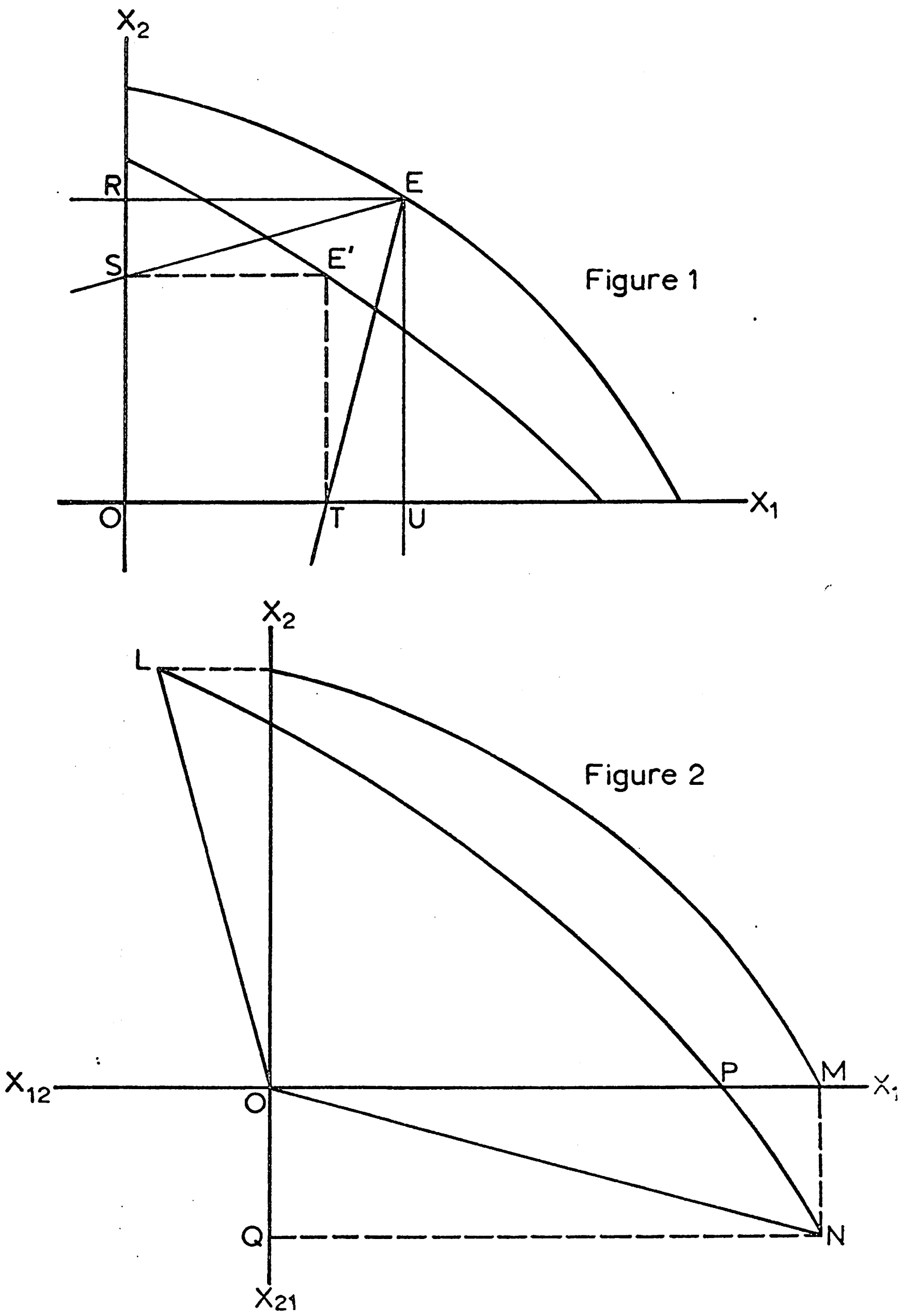


delivered to final demand is represented by $E^{\prime}$. He then goes on to show that the slope of the net curve is equal in absolute value to the price ratio, or

$$
\frac{d x_{2}}{d x_{1}}=-\frac{p_{1}}{p_{2}}
$$

There is, however, a serious difficulty with Vanek's diagram--the exclusion of trade in intermediate products, or to be more precise, ther exclusion of the possibility of a negative net production of one good, the required amounts of which are imported. This may be remedied by an extension of figure 1. In figure 2, the $x_{i j}$ axes measure the amount of $x_{i}$ used in the $j^{\text {th }}$ industry, and the factor proportion rays, OL and ON, are drawn from the origin, instead of from each point of the gross curve as in figure 1. Their slopes are, of course, $-a_{21}$ and $-1 / a_{12}$, respectively. We know that at $M$ (remember that $M$ can be found without knowing the $a_{i j}{ }^{\prime} s$ ) there is no output of $\mathrm{X}_{2}$ and that $\mathrm{a}_{12} \mathrm{X}_{1}$ or $\mathrm{QQ}$, of $\mathrm{X}_{21}$ is needed to produce OM of $X_{1}$. Therefore, the net curve must touch the factor proportion ray at $N$, and by symmetrical reasoning, at $L$. Since no substitution of $x_{21}$ for $\mathrm{K}_{1}$ and $\mathrm{L}_{1}$ is allowed, no further production of $\mathrm{X}_{2}$ can occur. Thus when the economy is producing between $P$ and $N$ on the net curve, it is using all the $\mathrm{x}_{2}$ to produce its export good, $\mathrm{x}_{1}$.

III. THE SINGLE FACTOR, VARIABLE PROPORTIONS MODEL

Georgescu-Roegen $^{3}$, Samuelson ${ }^{4}$, McKinnon $^{5}$, and Melvin ${ }^{6}$ have developed a model with a single primary factor and two intermediate/final goods, each

${ }^{3}$ Nicholas Georgescu-Roegen, 'Leontief's System in the Light of Recent Results," Review of Economics and Statistics, XXXII (Aug., 1950).

${ }^{4}$ paul A. Samuelson, "Abstract of a Theorem Concerning Substitutability 
used as inputs in the other industry, and with substitution between the inputs allowed. Thus they differ from Vanek by eliminating a primary factor but by allowing the intermediate input to be used in variable proportions. Assuming linear homogeneous production functions, they have used the total product curves to construct a net production function with a linear segment throughout the positive quadrant. The reader is referred to Melvin ${ }^{7}$ for a detailed construction of such a curve, and his Figure 1 is reproduced below as figure 3. The $x_{i j}$ are defined as above, and $f_{j}^{*}$ is the total product curve for $x_{i j}$ in the $j^{\text {th }}$ industry, with $L_{j}=L$. The model can be written as:

$$
\begin{aligned}
& x_{1}=f_{1}\left(x_{21}, L_{1}\right)-x_{12} \\
& x_{2}=f_{2}\left(x_{12}, L_{2}\right)-x_{21} \\
& L_{1}+L_{2}=I
\end{aligned}
$$

Since convex combinations of the two production processes are possible, the greatest possible output points are those on the line tangent to both total product curves, and $A B E F$ is the net production possibility curve, tangent to $f_{1}^{*}$ and $f_{2}^{*}$ at $B$ and $E$. It turns out that even though variable proportions of the intermediate inputs to outputs are allowed, between $B$ and $E$ in figure 3, efficient production requires proportions to be fixed, as would be expected from Samuelson's Substitution Theorem. ${ }^{8}$ In the $x_{2}$

in Open Leontief Models," Activity Analysis of Production and Allocation, edited by T. C. Koopmans (New York: John Wiley and Sons, Inc., 1951).

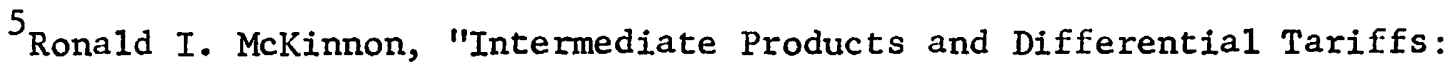
A Generalization of Lerner's Symmetry Theorem," Quarterly Journal of Economics, IXXX (Nov., 1966).

${ }^{6}$ James R. Melvin, "Intermediate Goods in Production Theory: The Differentiable Case," Review of Economic Studies, XXXVI (Jan., 1969), "Intermediate Goods, The Production Possibility Curve, and Gains from Trade," Quarterly Journa1 of Economics, IXXXIII (Feb., 1969), and "The Production Set When Iuabour is Indispensable," International Economic Review, 11 (June, 1970).

7 Melvin, "Intermediate Goods, The Production Possibility Curve, and Gains from Trade," op.cit., pp. 141-3.

8 Samuelson, op.cit., pp. 141-3. 


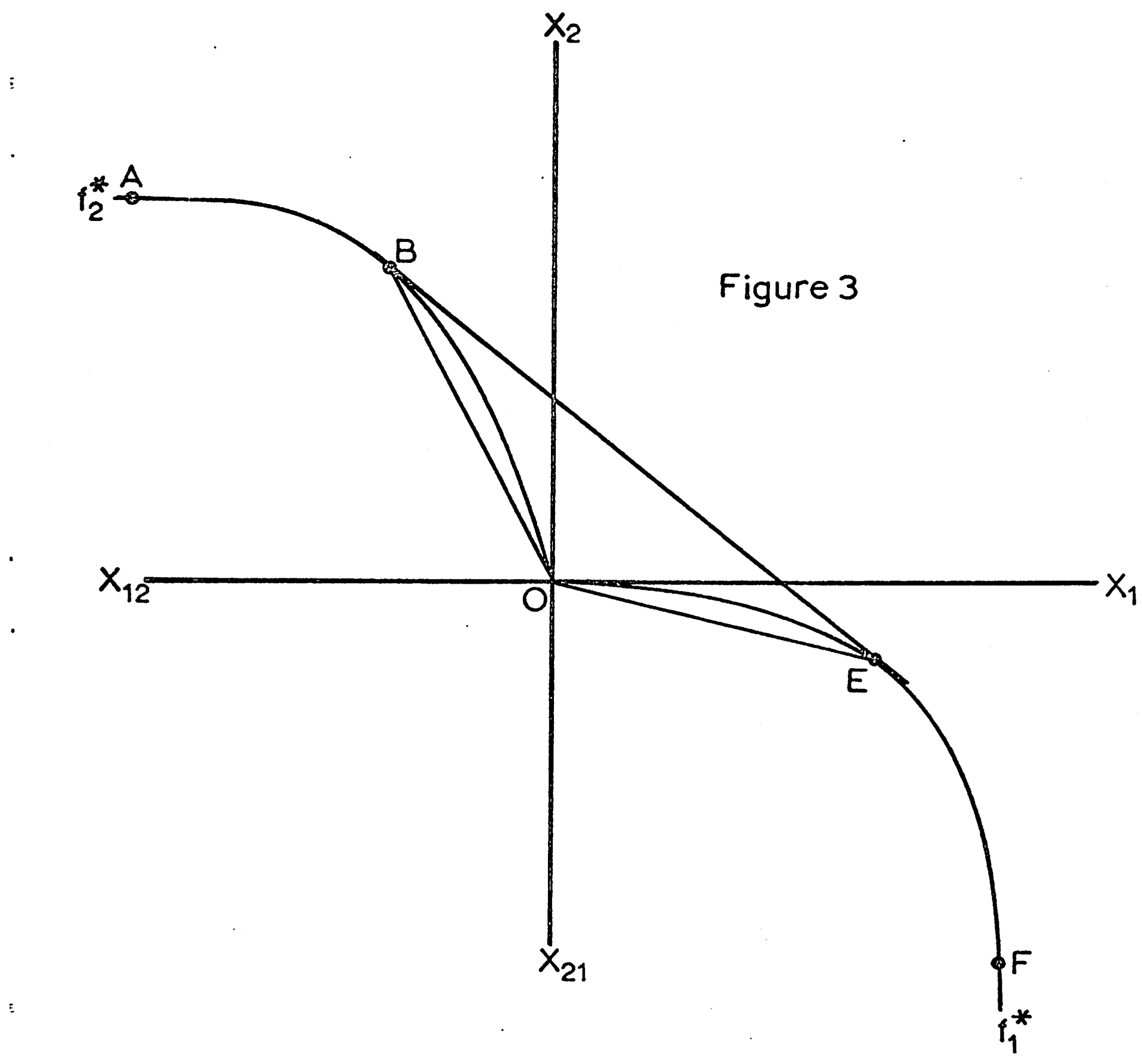


industry, for example, this constant proportion is represented by the line $O B$, which is equivalent to OL in figure 2.

\section{THE TWO FACTOR, VARIABLE PROPORTIONS MODEL}

The two previous models both consider special cases and therefore need to be generalized. A single primary factor does not correspond with reality--there are capital goods in the world. Of course, the offending assumption could be replaced by assuming two primary factors used in the same fixed proportions in all industries, but empirical evidence is clearly to the contrary. ${ }^{9}$ Further, international trade in such a model must be based on differences in production functions rather than differing factor proportions, which makes its implications difficult to apply to the body of trade theory that has grown around the Heckscher-Ohlin tradition.

Vanek's model, though avoiding the above criticisms, is still open to dispute, even when extended to include trade in intermediate products. He claims that "...the assumption of interindustry flows with constant coefficients is probably more realistic..."10 while incorporating variable proportions of the primary inputs. If an input which is not entirely consumed in production (capital) can substitute for labour, why should we expect, a priori, that an input that is consumed in production (an intermediate input) cannot substitute as well? For example, if more tractors will substitute in the production of wheat for less labour, surely so will more fertilizer.

9 Wassily Leontief, "Domestic Production and Foreign Trade; the American Capital Position Re-examined," Proceedings of the American Philosophical Society (Sept., 1953).

${ }^{10}$ Vanek, op. cit., p. 135 (italics added). 
We will now build a model incorporating variable proportions for al1 inputs and two primary factors, which will generalize the previous two models. ${ }^{11}$ Using the variables as defined above, we can write the model as follows :

$$
\begin{aligned}
& x_{1}=f_{1}\left(L_{1}, K_{1}, x_{21}\right)-x_{12} \\
& x_{2}=f_{2}\left(I_{2}, K_{2}, x_{12}\right)-x_{21} \\
& L_{1}+L_{2}=L \\
& K_{1}+K_{2}=K
\end{aligned}
$$

We assume that perfect competition prevails in all markets, that the production functions are continuous for all non-negative inputs, linear homogeneous, and twice differentiable, and that all marginal products are positive and diminishing. We further assume that perfect competition and profit maximization prevail, so that no inputs will be used when no output is being produced.

Since the $x_{i j} / x_{j}$ are not fixed, we cannot exclude the $x_{i j}$ from the arguments of $f_{1}$ and $f_{2}$ as was done in Vanek's model, which implies that the gross curve is no longer independent of the intermediate input requirements. This means we must derive our net and gross curves in a different manner than Vanek, since the gross curve is no longer both the total (gross) amounts produced and also the amounts that could be produced if intermediate inputs were not required. It is this latter interpretation that provides the anchor

${ }^{11}$ Vanek states, "...there would be no difficulty in defining and even constructing a production possibility locus where this assumption [fixed coefficients] is relaxed...." (Ibid., p. 135.) As we shall see below, it is not quite that simple. McKinnon merely assumes the existence of such a curve for the 3 good, $n$ factor case. See his fourth assumption (op. cit., p. 589.) Our 2 good, 3 factor model is a special case of his, and thus his theorems, where applicable, apply to our model. 
for Vanek's system, and it is just this interpretation that is no longer valid with variable proportions. To convince ourselves of this, take the special case in our model in which capital and labour are perfect substitutes--i.e., form one factor. But this is just the single factor, variable proportions model, which Melvin ${ }^{12}$ has shown capable of exploding; i.e., neither the gross curve nor the net curve necessarily have a finite existence. This problem cannot occur when no substitution of the intermediate input for the primary inputs is allowed. 13

We will first prove that the slope of the production possibility curve is equal to the negative of the price ratio $1 / \mathrm{P}$, where $\mathrm{P} \equiv \mathrm{P}_{2} / \mathrm{P}_{1}$. (Throughout the analysis $P_{1}$ will be the numeraire--factor prices $W \equiv w / P_{1}$ and $\mathrm{R} \equiv \mathrm{r} / \mathrm{P}_{1}$ will be treated accordingly.) Totally differentiating (4.1), $(4.2),(4.3)$, and (4.4) gives us:

$$
\begin{aligned}
& \mathrm{dx}_{1}=\mathrm{MPK}_{1} \mathrm{dK}_{1}+\mathrm{MPL}_{1} \mathrm{dL}_{1}+\mathrm{MPX}_{21} \mathrm{dX}_{21}-\mathrm{dX}_{12} \\
& \mathrm{dx}_{2}=\mathrm{MPK}_{2} \mathrm{dK}_{2}+\mathrm{MPL}_{2} \mathrm{dL}_{2}+\mathrm{MPX}_{12} \mathrm{dx}_{12}-\mathrm{dX}_{21} \\
& \quad \text { where } \mathrm{MPK}_{1} \text { is } \partial \mathrm{f}_{1} / \partial \mathrm{K}_{1}, \text { etc. } \\
& \mathrm{dK}_{1}=-\mathrm{dK}_{2} \\
& \mathrm{dL}_{1}=-\mathrm{dL}_{2},
\end{aligned}
$$

and from the marginal conditions for efficiency we know:

$$
\begin{aligned}
& \mathrm{MPK}_{1}=\mathrm{MPK}_{2} \mathrm{P}=\mathrm{R} \\
& \mathrm{MPL}_{1}=\mathrm{MPL}_{2} \mathrm{P}=\mathrm{W}
\end{aligned}
$$

${ }^{12}$ Melvin, "Intermediate Goods in Production Theory: The Differentiable Case," op. cit.

${ }^{13}$ Although it could "implode," if the Hawkins-Simon condition is not fulfilled. 


$$
\begin{aligned}
\mathrm{MPX}_{21} & =\mathrm{P} \\
\mathrm{MPX}_{12} & =1 / \mathrm{P}
\end{aligned}
$$

(Note that two new variables-- $\mathrm{X}_{12}$ and $\mathrm{x}_{21}$--and two new equations-- $(4.11$ and (4.12)--have been added to the usual non-intermediate goods mode1.)

$$
\begin{aligned}
& \text { Substituting (4.7) through (4.12) into (4.5) and (4.6) gives us: } \\
& \mathrm{dx}_{2}=\mathrm{MPK}_{2} \mathrm{dK}_{2}+\mathrm{MPL}_{2} \mathrm{dL}_{2}+\mathrm{dx}_{12} / \mathrm{P}-\mathrm{dx}_{21} \\
& \mathrm{dx}_{1}=-\mathrm{Pdx}_{2} \\
& \frac{\mathrm{dx}_{2}}{\mathrm{dx}_{1}}=-\frac{1}{\mathrm{p}}=-\frac{\mathrm{P}_{1}}{\mathrm{P}_{2}}
\end{aligned}
$$

Thus the slope of the net production possibility curve represents the price ratio for which the goods will exchange.

We begin to construct the production possibility curves by putting the total product curves, $f_{1}^{*}$ and $f_{2}^{*}$, into the diagram, as in figure 4 . These represent the amount of $x_{i j}$ required to produce $x_{j}$ when $K_{j}=K$ and $L_{j}=L_{\text {. }}$. For now, we assume that a common tangent exists which passes through the positive orthant of output space touching $f_{1}^{*}$ and $f_{2}^{*}$ at $C$ and $D$ respectively. The assumption of constant returns to scale implies that with one hall the inputs required of each industry at $\mathrm{C}$ and $\mathrm{D}\left(\mathrm{K}_{1}=\mathrm{K}_{2}=\frac{1}{2} \mathrm{~K}\right.$ and $\mathrm{L}_{1}=\mathrm{L}_{2}=$ $\frac{1}{2} L$ ) we can produce at $B$; a reshuffling of factors will yield a greater amount of output than at $B$, since advantage can then be taken of the differing factor intensities of the goods. This implies the net curve must lie above the tangency line. Furthermore, it must be everywhere smooth, continuous, and concave to the origin, since convex combinations of any two points on the curve are feasible.

An important question is whether or not the net curve becomes tangent to the total product curves at the point where they have zero and infinite 


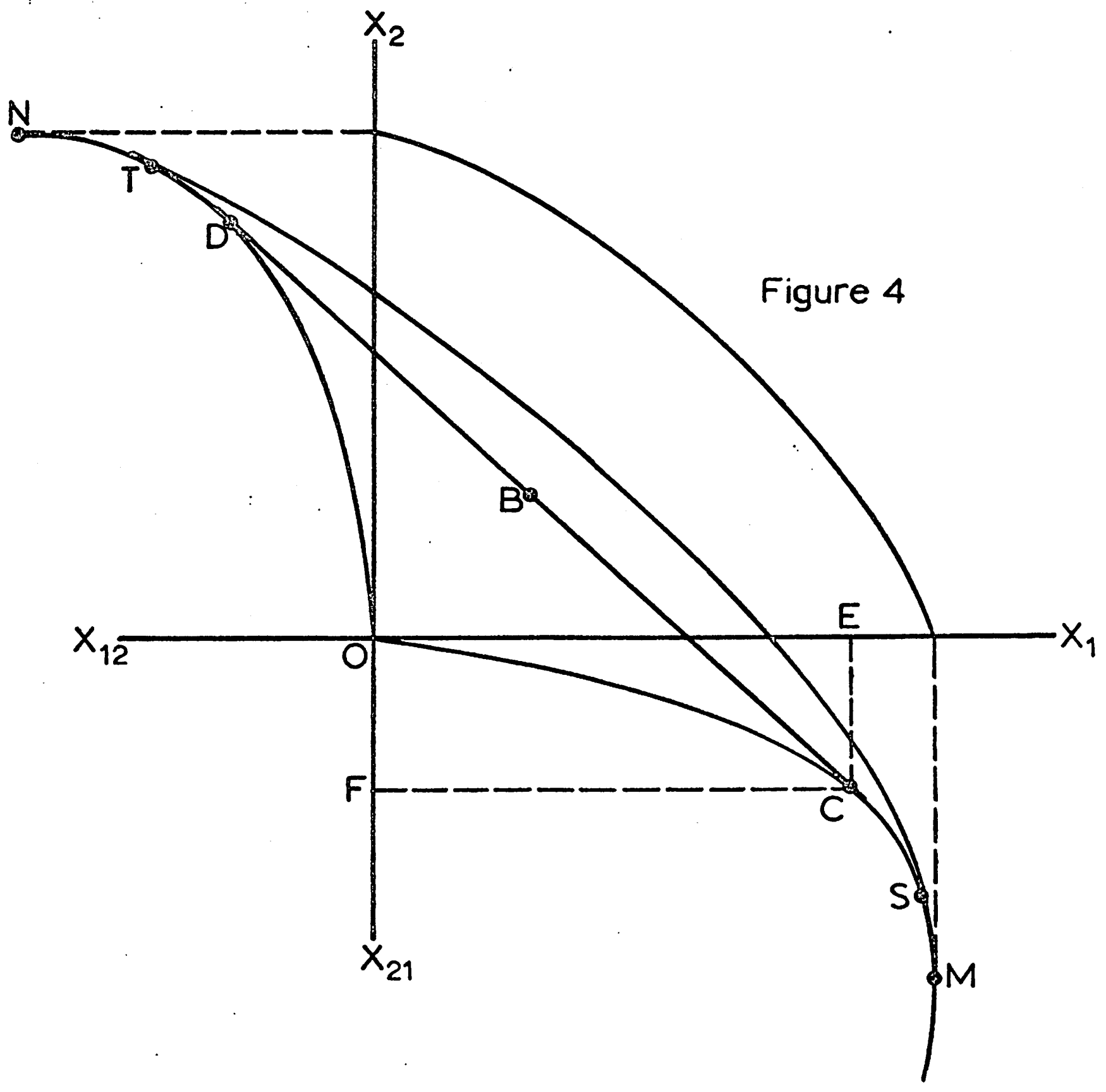


slopes. If it does that country would never gross specialize ${ }^{14}$ unless the good became free, a result of great importance for factor price equalization. This possibility is obviously restricted to cases in which $f_{1}^{*}$ and $f_{2}^{*}$ reach maxima, so let us consider that case. 15

Call the maxima points of $f_{1}^{*}$ and $f_{2}^{*}, M$ and $N$ respectively. Call the points where the net curve touches $f_{1}^{*}$ and $f_{2}^{*}, S$ and $T$, and the points of tangency of a straight line with $f_{1}^{*}$ and $f_{2}^{*}, C$ and $D$. The net curve must touch at points of tangency since the slope of the net curve has been shown to be $1 / P$ and the slope of $f_{i}^{*}$ will be the $\mathrm{MPX}_{i j}$ which also will equal $1 / P$. Alternatively, an appeal to the properties of smoothness, continuity, and concavity to the origin established above for the net curve also achieves this result. So $S$ and $T$ must lie somewhere along $f_{1}^{*}$ and $f_{2}^{*}$ beyond $C$ and $D$. Consider the following theorem:

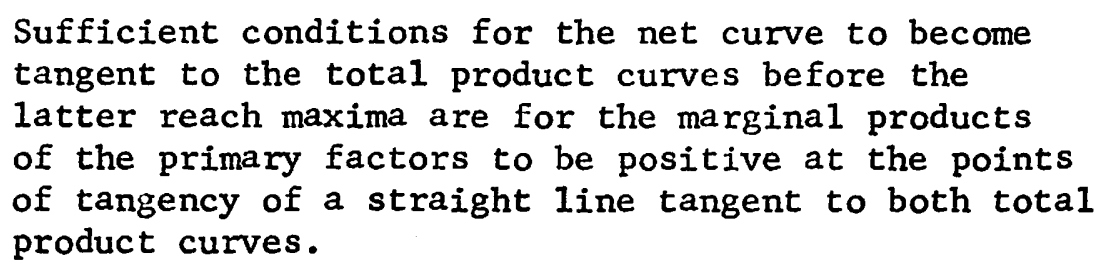

In terms of figure 4 , $S$ lies between $C$ and $M$ if the marginal products of capital and labour are positive at $C$. (We will consider only point S throughout the proof of the theorem, since identical reasoning applies to point $T$. We begin the proof by noting that the question of whether the net curve becomes tangent to $f_{1}^{*}$ before the latter reaches a maximum is the same as the question of whether there is a positive $P$ at which $X_{2}$ will no longer

14 We define gross specialization to occur when a country produces none of one of the goods.

${ }^{15}$ There are similarities in the problems of maxima of the total product curves and boundedness of the production set between this model and the one with which Melvin is concerned. For his discussion of the problems involved see his "Intermediate Goods in Production Theory: the Differentiable Case," op.cit., and "The Production Set When Labour is Indispensible," op.cit. 
be produced domestically, and $a 11 \mathrm{x}_{21}$ will be imported. This can be seen by observing that at $S, K_{1}=K$ and $L_{1}=L$, so that no $x_{2}$ is being produced. If in the first industry neither the $M P L_{1}$ nor the $M_{F K}$ is zero at $C$, neither marginal product can become zero as more and more of the intermediate product is added, i.e., as we move along $f_{1}^{*}$ to $M$. This follows from the assumptions of constant returns to scale and diminishing marginal products, which together imply that if the quantities of two factors are fixed and additional amounts of a third factor are added, the marginal products of the first two will increase, and in particular, cannot become zero. Furthermore, if $M P L_{1}$ and $M P K_{1}$ are not zero anywhere beyond point $C, W$ and $R$ are positive in that range.

Next we note that in the second industry:

$$
\begin{aligned}
& \text { Total Revenue }=(\mathrm{P})\left(\mathrm{X}_{2}\right) \\
& \text { Marginal Revenue }=\mathrm{P} \\
& \text { Total Cost }=\mathrm{L}_{2} \mathrm{~W}+\mathrm{K}_{2} \mathrm{R}+\mathrm{X}_{12} \\
& \text { Margina1 Cost }= \\
& \qquad \mathrm{d}) \frac{\mathrm{dL}}{\mathrm{dX}_{2}}+\left(\mathrm{L}_{2}\right) \frac{\mathrm{dW}}{\mathrm{dX}_{2}}+(\mathrm{R}) \frac{\mathrm{dK}_{2}}{\mathrm{dx}_{2}}+\left(\mathrm{K}_{2}\right) \frac{\mathrm{dR}}{\mathrm{dX}}+\frac{\mathrm{dX}_{12}}{\mathrm{dx}_{2}},
\end{aligned}
$$

and

$$
\lim _{X_{2} \rightarrow 0} M C_{2}=\lim _{X_{2} \rightarrow 0}\left[(W) \frac{\mathrm{dL}_{2}}{\mathrm{dX}_{2}}+(\mathrm{R}) \frac{\mathrm{dK}_{2}}{\mathrm{dX}_{2}}+\frac{\mathrm{dX}_{12}}{\mathrm{dX}_{2}}\right]
$$

From our assumption of perfect competition and profit maximization, $I_{2}$ and $K_{2}$ go to zero as $x_{2}$ goes to zero, so that the terms with $L_{2}$ and $K_{2}$ are excluded from $(4.14)$.

We have just established that $W$ and $R$ remain positive as $X_{2}$ goes to zero. They must also be finite since output is finite. However, since at any equilibrium output $\mathrm{dL}_{2} / \mathrm{dK}_{2}=\mathrm{R} / \mathrm{W}$, which is positive and finite, 


$$
0<\frac{\frac{\mathrm{dL}_{2}}{\mathrm{dx}_{2}}}{\frac{\mathrm{dK}_{2}}{\mathrm{dx}_{2}}}<\infty
$$

Therefore, the terms $\mathrm{dL}_{2} / \mathrm{dx}_{2}$ and $\mathrm{dx}_{2} / \mathrm{dX}_{2}$ remain positive as $\mathrm{X}_{2}$ goes to zero. (They, as well as $\mathrm{dx}_{12} / \mathrm{dx}_{2}$, can never be negative since $\mathrm{L}_{2}, \mathrm{~K}_{2}$, and $\mathrm{X}_{12}$ must decrease to zero as $\mathrm{x}_{2}$ decreases to zero.)

Hence, from (4.14) $\mathrm{MC}_{2}$ remains positive as $\mathrm{X}_{2}$ goes to zero. But efficiency conditions dictate that production will not take place when $\mathrm{P}<\mathrm{MC}_{2}$. Thus, there exist positive price levels (smaller than the limiting $\mathrm{MC}_{2}$ of (4.14)) at which $\mathrm{X}_{2}$ is not produced, and the theorem is established. $C$ and $M$ could coincide, on the other hand, if the difference in factor intensities is such that the second industry uses only one input--a primary one--in the limit as $\mathrm{x}_{2}$ approaches zero, and if the marginal product of that factor in the first industry is zero at $M$ (so that its return is zero). In this case, $\mathrm{MC}_{2}$ (and $\mathrm{P}$ ) would approach zero as $\mathrm{X}_{2}$ did, and $S$ could not touch $f_{1}^{*}$ at a point nearer the origin than $M$, the first point along $f_{1}^{*}$ at which $P$ becomes zero.

As we have drawn figure 4, the net curve becomes tangent to the total product curves before they reach finite maxima, and thus the net product curve is NTSM.

\section{SOME IMPLICATIONS}

Melvin $^{16}$ and McKinnon ${ }^{17}$ reach conclusions which depend crucially on the special assumptions of their mode1--one primary factor only and differences in production functions forming the basis of trade--and which do not hold in the more general model we have developed. In particular, it is the

${ }^{16}$ Melvin, "Intermediate Goods, the Production Possibility Curve, and Gains from Trade," 오. cit.

17 Mckinnon, op. it. 
resulting production function which is linear throughout the positive quadrant that gives rise to the special conclusions which they draw. Melvin ${ }^{18}$ uses two countries' production blocks to derive the world consumption possibility set for the cases in which trade in intermediate goods is and is not allowed. See figure 5.19 He then shows that the consumption set with trade in intermediate goods allowed, M'RN' "strictly contains the consumption set of MO'N." ${ }^{20}$ It is easily seen, however, that this is because production is never efficient when both countries are simultaneously on the linear portions of their production curves and when trade in intermediate goods is allowed. Any price level different from the one that corresponds to the linear segment of the production possibility curve causes net specialization. 21 when trade in intermediate goods is not allowed, however, production must always take place on the linear portions of the curves. Hence trade in intermediate products allows greater world consumption at all price ratios.

With our more general model, however, a portion of the two world consumption sets may coincide, and in fact a necessary and sufficient

${ }^{18}$ Melvin, "Intermediate Goods, the Production Possibility Curve, and Gains from Trade," 오. cit.

${ }^{19}$ Figure 5 is essentially the same as Melvin's (ibid., p. 146). 20 Ibid., p. 147 .

${ }^{21}$ Net specialization is said to occur when the net production of a good is non-positive. 

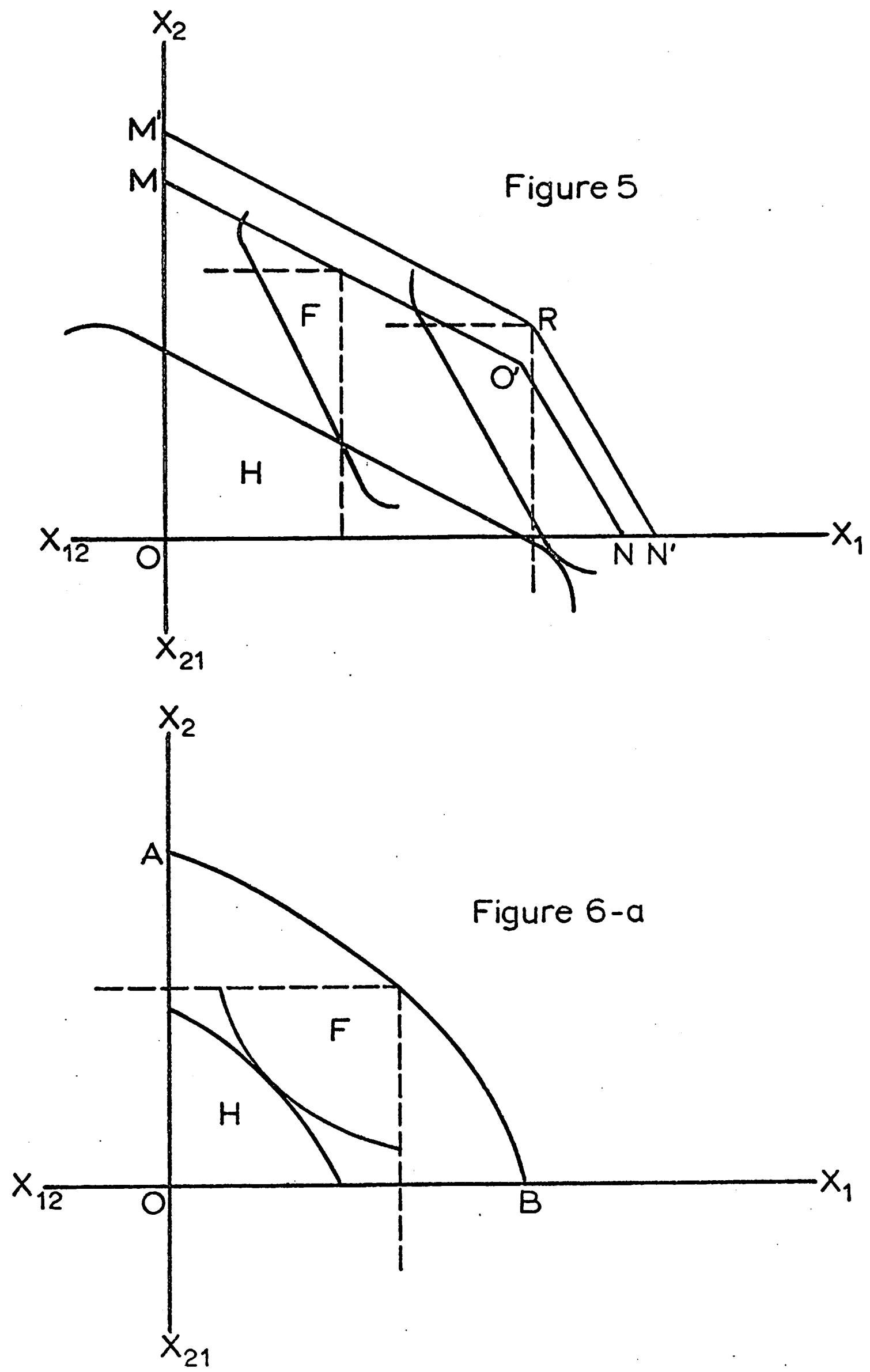
condition for this to occur is for the portion of each country's net production possibility curve which lies in the non-negative quadrant to have at least one price ratio in common. ${ }^{22}$ In figure 6-a we derive the world consumption set, $A B$, for the case in which trade in intermediate products is not allowed. The method and result are of course the same as the traditional non-intermediate good model. 23

In figure 6-b we do the same thing using the full net production possibility curves derived above. Note that as we slide the production block of $F$, the second country, along $\mathrm{H}^{\prime} \mathrm{s}$, the intersection of the nonnegative quadrants must not become non-empty (since the world cannot produce negative net amounts). The resulting world consumption possibility set, $A^{\prime} B^{\prime}$, will clearly coincide with $A B$ over that range in which neither country is net specializing, $C D$; for over this range the availability of trade in intermediate goods is of no benefit. $C D$, of course, corresponds to the range of slopes that the two net curves have in common in the non-negative quadrant.

In other words, the one primary factor model ensures net specialization in at least one country at all world price ratios so that prohibition of trade in intermediate products will always decrease total output. In the more general model, however, a large portion of the world consumption curve may be the same whether or not intermediate goods trading is prohibited.

${ }^{22}$ Note that this theorem can be applied to Melvin's model as we11, and that the condition stated is never fulfilled.

${ }^{23}$ Abba P. Lerner, "The Diagrammatical Representation of Cost Conditions in International Trade," Economica, XII (Aug., 1932). 

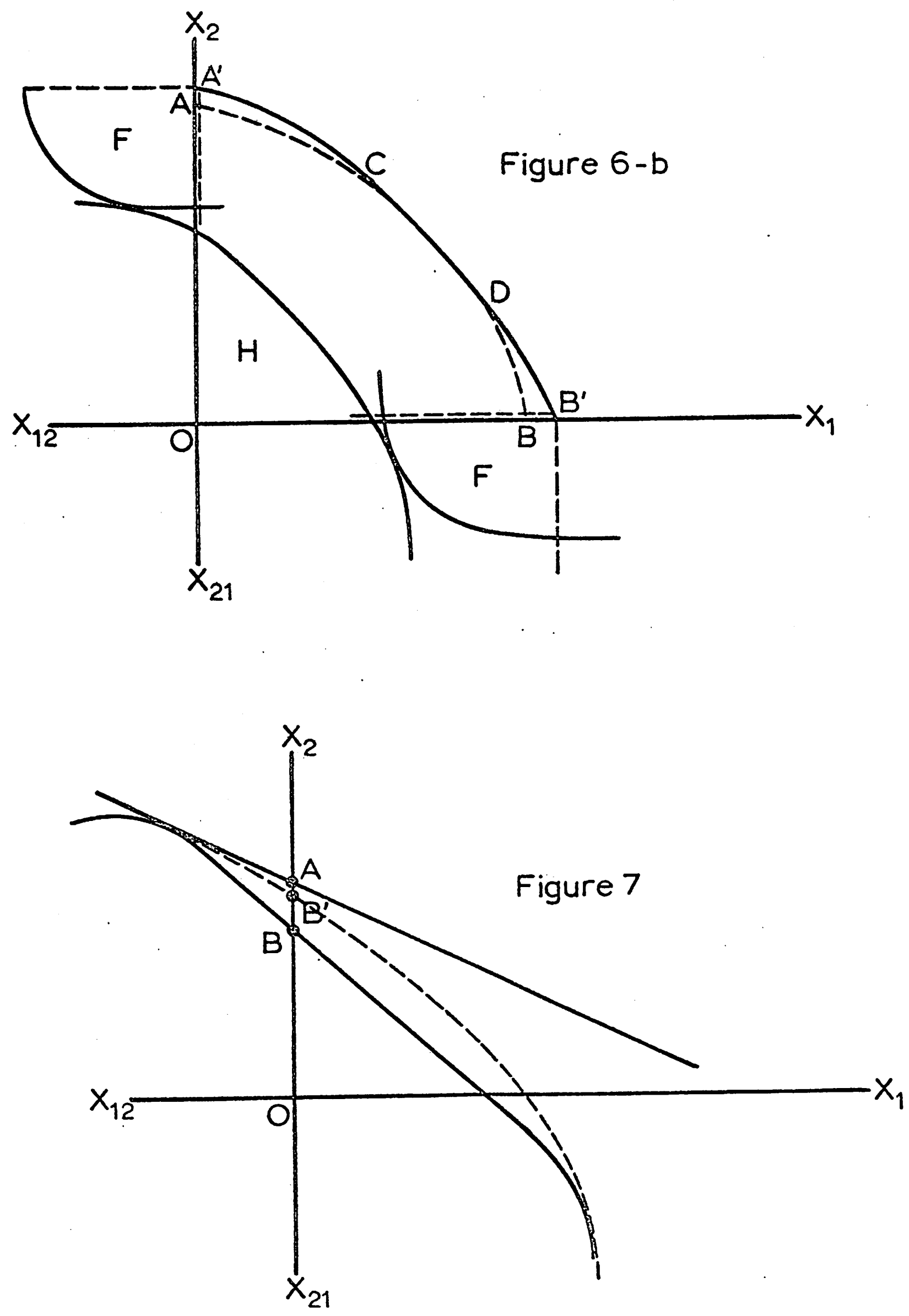
Mckinnon $^{24}$ is subject to much the samx: sort. of criticism. In Section III of his paper he responds to Harry Johnson's ${ }^{25}$ attempt to meisure the gains from international trade. McKinnon feels Johnson's estimates are biased downward by the exclusion of intermediate goods from his model, and uses the one primary factor, one intermediate good model to compute the gains from trade measured in terms of the exported good. His Figure $I I I^{26}$ is essentially reproduced as figure 7 , and what he computes is the ratio $O B$ : $O A$ for various changes in price ratio from autarky to free trade.

McKinnon's analysis can be criticized on two grounds. First, his choice of models guarantees net specialization when the price ratio differs from its autarky level. In the general model net specialization can only occur if in figure 6-b world consumption takes place on either $A^{\prime} C$ or DB'. In the intermediate range, $C D$, total production is unaffected by the possibility of trade in intermediate goods. Second, McKinnon's model overestimates the gains from trade since a bowed out net curve increases autarky production of $\mathrm{x}_{2}$, i.e., $\mathrm{OB}: \mathrm{OA}<\mathrm{OB}^{\prime}: \mathrm{OA}$ in figure 7 .

${ }^{24}$ Mckinnon, op. cit., pp. 604-610.

${ }^{25}$ Harry C. Johnson, "The Costs of: Protection and Sclf-Sufficiency," Quarterly Journal of Economics, LXXIX (Aug., 1965).

26 Mckinnon, op. cit., p. 607 . 